\title{
Examining Low-Income Single-Mother Families' Experiences with Family Benefit Packages during and after the Great Recession in the United States
}

\author{
Yu-Ling Chang ${ }^{1, *(1)}$ and Chi-Fang $\mathrm{Wu}^{2}$ \\ 1 School of Social Welfare, University of California, Berkeley, 120 Haviland Hall MC 7400, Berkeley, \\ CA 94720, USA \\ 2 School of Social Work, University of Illinois at Urbana-Champaign, 1010 West Nevada Street, Urbana, \\ IL 61801, USA; cfangwu@illinois.edu \\ * Correspondence: ylchang@berkeley.edu
}

check for updates

Citation: Chang, Yu-Ling, and Chi-Fang Wu. 2021. Examining Low-Income Single-Mother Families' Experiences with Family Benefit Packages during and after the Great Recession in the United States. Journal of Risk and Financial Management 14: 265. https://doi.org/10.3390/ jrfm14060265

Academic Editor: Mark Harris

Received: 19 May 2021

Accepted: 8 June 2021

Published: 11 June 2021

Publisher's Note: MDPI stays neutral with regard to jurisdictional claims in published maps and institutional affiliations.

Copyright: (c) 2021 by the authors. Licensee MDPI, Basel, Switzerland. This article is an open access article distributed under the terms and conditions of the Creative Commons Attribution (CC BY) license (https:/ / creativecommons.org/licenses/by/ $4.0 /)$.

\begin{abstract}
The recent economic recession triggered by the global pandemic has renewed scholarly interest in the role of social welfare systems in supporting economically vulnerable families when they experience employment instability. This article unpacks the patterns of the cash and in-kind components of the monthly family benefit packages that US low-income single mothers accessed during and after the Great Recession. We used the 2008 Survey of Income and Program Participation and an innovative analytic procedure involving family benefit package plots, group-based trajectory modeling, and logistic regression modeling. We found that low-income single mothers more often used in-kind basic-needs packages and less often used packages that bundle a cash benefit or a childcare subsidy, regardless of their dynamic employment status. Our findings challenge the effectiveness of the US work-based welfare system in ensuring the economic security of economically vulnerable families and contribute to the policy discussions on unconditional basic income and President Biden's American Families Plan.
\end{abstract}

Keywords: family benefit package; Great Recession; single mothers in poverty; group-based trajectory modeling; UpSet plots

As the COVID-19 pandemic sends the global economy into another recession, governments and policymakers have proposed urgent policy responses to ensure the economic and health well-being of affected families and recovery plans when the public health crisis eases. This article contributes to the current conversation about policy responses to support economically disadvantaged working families to recover from the COVID-19 pandemic by examining the role of the US social welfare system in supporting low-income single-mother families and discussing the lessons of the last global economic recession.

The US welfare system is distinct from those in other industrialized counties in its exceptionally fragmented programs and stratified benefits that target various sociodemographic groups, such as single mothers, unemployed workers, seniors, and people with disabilities (Meyers and Gornick 2009). Economic deregulation that accelerated in the 1980s has led to increasing income inequity, and the privatization of welfare services has weakened many public goods and services and excluded poor individuals and families from accessing the social safety net (Fortin and Lemieux 1997; Lee 2008). Ronald Reagan's administration laid the groundwork for the welfare reform legislation passed by Bill Clinton in 1996, ascribing deficit spending by the federal government to poor Americans' laziness or free-riding on welfare benefits (Seccombe 1999). Reagan created a political identity, the "welfare queen", arguing that unconditional support from the government amounted to "reverse discrimination" by income (Hancock 2003). In this, he referenced racist stereotypes of Black people as lazy and irresponsible (Seccombe 1999). The welfare reform law of 1996 included a turn toward for community-oriented, faith-based initiatives, which resulted in increased involvement of religious social service agencies for anti-poverty 
services, increasing the social safety net system's fragmentation (Gilman 2006; Queen 2017). Welfare reform also dismantled the need-based system in favor of a "work-based" system in which work has become a condition for public cash benefits for working-aged adults (Danziger et al. 2016; Hardy et al. 2018). Policy discourses underlying welfare reform were racialized stereotypes of lazy, unmarried African American mothers who depended on welfare and who should be forced to participate in the labor force to achieve self-sufficiency (Seefeldt 2017).

A work-based system particularly disadvantages low-income single mothers, who often hold low-wage, unstable jobs and shoulder both wage earning and caregiving responsibilities in their families. The erosion of public cash benefits since welfare reform has attracted scholarly attention to the "economic disconnection" - from both the welfare and labor market systems-of single-mother families and the negative impacts on children (Cancian et al. 2014; Hetling et al. 2015; Kwon and Meyer 2011; Seefeldt and Horowski 2012; Slack et al. 2014). A work-based system imperils single mothers in economic hardship in periods when work is scarce, such as the recent Great Recession (GR, 2007-2009), during which single mothers had higher unemployment rates than married mothers and childless women (Mattingly et al. 2011). Although several social welfare programs temporarily expanded eligibility or benefits under the American Recovery and Reinvestment Act of 2009 (ARRA 2009) to assist families affected by the economic downturn (Chang 2015; Chang and Romich 2021), children from single-parent families still experienced a larger increase in the poverty rate than children from married-couple families (Bitler et al. 2017).

While US social policy scholars have studied social welfare programs for workingage families by analyzing aggregate annual policy performance (e.g., changes in welfare expenditure; the effects of poverty reduction) over macroeconomic cycles (Bitler and Hoynes 2016; Bitler et al. 2017; Moffitt 2013), much less is known about how low-income single-mother families bundled different benefits to sustain themselves month to month during the GR and its recovery period (Seefeldt and Sandstrom 2015; Waring and Meyer 2020). Adopting a family benefit package perspective, this article focuses on low-income single-mother families' experience of seven major public cash and in-kind benefits that support monthly family economic resources. We used a nationally representative panel sample from the 2008 Survey of Income and Program Participation (SIPP) and an innovative analytic approach involving family benefit package plots, group-based trajectory modeling (GBTM), and (multinomial) logistic regression modeling to unpack the relationship between multiple program participation and dynamic employment status over a five-year study period. The results reveal that family benefit packages varied considerably by employment status, but mothers were more likely to use in-kind basic-needs packages than other packages that bundle a cash benefit or a childcare subsidy. This finding is inconsistent with the theoretical assumption that cash benefits serve as primary resources in a family benefit package to effectively improve family economic security, particularly when mothers' work capacity or employment opportunities are limited. The results shed light on the limitations of the US work-based welfare system and on the importance of a comprehensive family benefit package including the monthly basic income support.

\section{Literature Review}

1.1. Components of Monthly Family Benefit Packages for Economically Disadvantaged Families in the US

Public social welfare programs that support family monthly expenses in the US typically include contribution-based social insurance and means-tested social assistance programs that provide cash or in-kind transfers to economically disadvantaged families who have difficulty meeting basic needs due to low income or job loss (Chang 2015). Social insurance is tied to past work in the formal labor market and financed in part by payroll tax contributions. Social assistance is means-tested (applicants' family income and assets must be below a certain amount for them to be eligible) and financed through general revenue streams. Means-tested benefits decline in value as family earnings increase. Since welfare reform, tax credits for families with low earned income have expanded as part of 
the US work-based welfare system to "make work pay" (Meyers and Gornick 2009). Lowincome families often piece together benefits from multiple programs to make ends meet (Seefeldt et al. 2013). Social policy scholars have described this bundling as the creation of family benefit packages, which typically include cash benefits and in-kind goods and services (Allard et al. 2015; Meyers 2007; Meyers et al. 2001; Seefeldt and Sandstrom 2015). Theoretically, cash benefits are considered primary resources for low-income families because they directly supplement insufficient earnings due to unemployment or lowpaying jobs and have high flexibility because they can be spent on different needs. In contrast, in-kind or tax benefits are considered secondary resources that support families by reducing expenditures on basic necessities or relieving tax burdens (Seefeldt and Horowski 2012). Using a family benefit package perspective to understand a welfare system is critical because this perspective offers insights into how the components of cash and in-kind benefits bundle together to safeguard economically vulnerable families from hardship. The current study focuses on three cash benefits and four in-kind benefits, in any combination: Unemployment Insurance (UI), Supplemental Security Income (SSI), Temporary Assistance for Needy Families (TANF), the Supplemental Nutrition Assistance Program (SNAP), Medicaid (MA), housing assistance (HA), and subsidized childcare (CC). Although these programs represent only a subset of all US social welfare programs, they are the most common monthly cash and in-kind assistance available to low-income working-age families. The Earned Income Tax Credit (EITC) and the Child Tax Credit (CTC), while significant programs, are typically collected annually and thus may not augment family economic resources month-to-month.

Studies on social welfare programs in the US have taken a macrolevel approach, analyzing national trends in program participation rates for a variety of social welfare programs (e.g., Bitler and Hoynes 2010, 2016; Moffitt 2013). These studies have indicated that UI and SNAP provided more protection than means-tested cash benefits for working families during the GR. Relatively little research has focused on low-income single-mother families, despite their known economic disadvantages. For example, Eamon and Wu (2013) used 2004 and 2008 SIPP panel data and found substantial increases in program participation for all programs except TANF and slight increases in participation duration o for all programs except SSI among low-income single mothers. This program-by-program analytic approach provides an overview of the single-program participation rate and average benefit duration but does not address the combined use of different benefits on a monthly basis.

Because TANF (which replaced the Aid to Families with Dependent Children program, which existed 1935-1995) has historically primarily served low-income single-mother families, prior studies on joint or multiple program participation among single mothers have often focused on TANF, examining how TANF receipt combines with other benefits (Cancian et al. 2005; Cancian et al. 2014; Seefeldt et al. 2013). More recent studies on joint/multiple program participation have made UI or SNAP the focal program; both of these benefits expanded substantially in response to the GR (e.g., Finifter and Prell 2013; Moffitt 2014; O'leary and Kline 2014). However, these recent studies reveal little about how the bundling patterns of cash and in-kind benefits differ by employment status over time, knowledge that is necessary to better understand the economic lives of low-income, single-mother families in the US work-based welfare system.

\subsection{Patterns of Post-Welfare Reform Employment Among Low-Income Single Mothers}

A large body of research on employment status among low-income single mothers has investigated the post-program employment of TANF leavers (e.g., Acs and Loprest 2004; Cancian et al. 2002; Danziger et al. 2002; Wood et al. 2008; Wu et al. 2008). These studies have found that approximately two-thirds participated in the labor force in the first year, but job instability was common. While this line of research answered an important question regarding how low-income mothers fared after leaving TANF, its relevance to contemporary policymaking is low for two reasons. First, most studies on TANF partici- 
pants were conducted during the mid-1990s to early 2000s, a booming economic period with low unemployment rates. Concerns have been raised about the impacts of economic downturns on employment among low-income single mothers in the post-welfare reform era (Blank 2006). Second, given its decreasing caseload and program restrictions (e.g., the 60-month lifetime benefit limit and work requirements), TANF no longer serves a significant proportion of low-income families over economic cycles (Bitler and Hoynes 2010; Moffitt 2013). Employment pattern findings based on TANF leavers can thus not be generalized to the population of low-income single mothers in the US.

Studies on the patterns of employment among low-income single mothers over time typically adopt one of two approaches. The first approach is to analyze the trend in the aggregate employment rate. For example, Kim and Joo (2009) found that 31\% of lowincome single mothers receiving TANF benefits were employed in 1996, 46\% in 2001, and $40 \%$ after the mild economic recession in 2004. A major limitation of this analytic approach is that it does not capture dynamic employment status or reflect the diversified employment trajectories among low-income single mothers. The second approach is to analyze individual patterns of employment using longitudinal data (Achdut and Stier 2016; Johnson 2007; Wood et al. 2008; Wu et al. 2008; Wu 2011). Wu et al. (2008) and Wu (2011) identified seven employment trajectories based on level, trend, and stability of employment. These studies showed that 46-65\% of low-income mothers experienced a successful employment trajectory (i.e., stable employment, increasing employment, or unstable employment with a positive ending) after welfare reform and before the GR. However, these works defined the employment trajectory by heavily weighing the last data point, failing to capture the gain or the loss of employment that occurred at any middle point in time during the study period. The current study improves upon these earlier studies by using GBTM, which factors in multiple data points equally to cluster people who experience similar trajectories (Nagin 2005). It also analyzes the heterogeneous program participation experience of mothers with different employment trajectories following the GR to provide a more complete picture of low-income single-mother families' economic lives from a longitudinal perspective.

\subsection{Monthly Family Benefit Packages and Employment Status in the US Work-Based Welfare System}

The US work-based welfare system is built upon a central assumption: able-bodied adults are responsible for their economic security through employment. Therefore, social welfare programs are designed to help able-bodied adults quickly transit from unemployment to employment and maintain employment to achieve self-sufficiency. Based on this assumption, family benefit packages differ by employment status because programs have different eligibility rules related to work history and work status/employability. The three cash benefits operate through different mechanisms to uphold the work-based system. UI provides wage replacement to those who lose a job through no fault of their own and requires recipients to actively seek (full-time) jobs or attend certified training. TANF is conditioned on work-related activities (e.g., employment, training, and education, etc.) and sanctions participants who do not have jobs or participate in federally allowed activities, although those with very young children or a work-limiting health condition may be exempted. SSI is conditioned on physical or mental disability status and therefore serves people with limited employability. The four in-kind benefits support low-income working families in two ways. First, similar to TANF, CC is available only to low-income families with dependents who engage in work-related activities. Second, SNAP, MA, and HA benefits, typically not conditioned on past or current work activities, address the unmet basic needs of low-income families when their earnings are insufficient to make ends meet.

Research has analyzed the family income packages for economically vulnerable families by conducting cluster analysis of employment status and benefit receipt from multiple programs simultaneously at a single point in time (Slack et al. 2014; Yang et al. 2019). The resulting typologies have shown that unemployment is associated with the receipt of multiple benefits. However, these cluster analyses did not illuminate how monthly family benefit 
packages change as employment status changes. To understand the extent to which the US work-based system effectively supports economically disadvantaged working families, one must study the bundling patterns of monthly cash and in-kind benefits among low-income single mothers who experience unstable employment during an economic recession and the recovery period.

\subsection{The Current Study}

The aim of the current study is to (i) analyze monthly patterns of participation in seven social welfare programs among low-income single mothers during the GR and its aftermath, (ii) identify five-year employment trajectories among low-income single mothers and the associated sociodemographic characteristics and patterns of program participation, and (iii) examine how low-income single mothers who experienced unstable employment trajectories pieced together different cash and in-kind programs when they transited into and out of employment. For (ii) and (iii), this paper does not seek to test the causal relationship between program participation and employment but rather to unpack the complex relationship between different types of family benefit packages and changing employment status over time. Based on a theoretical assumption regarding family benefit packages that cash benefits function as primary income support for families with low or reduced income (Seefeldt and Horowski 2012), we hypothesize that in an ideal packaging pattern, low-income working mothers would use a family benefits package featuring cash benefit TANF as the primary benefit, supplemented by in-kind CC or/and basic needs benefits, and that low-income nonworking mothers would use a family benefits package featuring cash benefit UI or SSI as the primary benefit, supplemented by in-kind basic-needs benefits.

\section{Methods}

\subsection{Data and Sample}

We used the Census Bureau 2008 panel of the SIPP. The dataset covers mid-2008 through 2013 and includes detailed information on household economic resources and individuals' employment status obtained from a nationally representative sample. Our sample ( $\mathrm{N}=870)$ selection criteria were as follows: single mothers aged 18-64 whose family earned income was under $200 \%$ of the federal poverty line in the baseline (first) month, who had at least one resident minor child in the household in the baseline month, and for whom 60 monthly data points from Wave 1 through Wave 15 had been recorded. To reduce potential bias due to sample attrition, we weighted all of the analyses using the five-year longitudinal weight offered by the Census Bureau (see details in Westat and Mathematica Policy Research 2001).

\subsection{Measurements}

Program participation and family benefit packages: Monthly program participation was defined as whether a family had participated in a given program in a given month. We created two five-year program participation variables by aggregating information on monthly program participation: Ever program participation was defined as whether a family had participated in a given program during the five-year study period. The cumulative benefit duration for each program was defined as the total number of months a family participated in a given program. Family benefit packages refer to participation in different combinations of programs in a given month. To identify the patterns of the cash and in-kind components of family benefit packages, in some analyses, we classified UI, TANF, and SSI as cash benefits and SNAP, MA, and HA as in-kind basic-needs benefits (not conditioned on work). CC stands alone as a type of in-kind, work-support benefit (conditioned on work).

Employment status and employment trajectory: A dichotomous variable measured participants' monthly employment status (no/yes). We then used the time-varying employment status from month 1 to month 60 to classify our sample into five distinct employment 
trajectories using GBTM: stable employment, stable nonemployment, decreasing employment, slow employment recovery, and fast employment recovery (see detailed information in the analytic procedures section).

Sociodemographic characteristics: We measured the self-sufficiency level by calculating the family earned income-to-poverty level (IPL, in percent). Self-sufficiency was defined by an IPL equal to or above $200 \%$. Other sociodemographic characteristics were age, high school diploma (yes/no), race/ethnicity (White, African American, Hispanic, Asian), work-related disability (yes/no), number of other adults in the family, number of children, age of the youngest child, homeownership (yes/no), metro area (urban/rural), marital status (married, never married, separated/divorced/widowed), and citizenship (yes/no). All these variables were time-varying (by month).

\subsection{Analytic Procedures}

To address the first aim of analyzing the patterns of program participation, we first used weighted statistics to describe the ever program participation rate and the average cumulative benefit duration for the seven programs. Further zooming in on monthly patterns in family benefit packages, we used UpSet, a set visualization tool, to analyze the frequency and the intersection of participation in different programs. The UpSet analytic tool overcomes the challenge of analyzing the co-occurrence between multiple sets (here, programs) because when considering $\mathrm{n}$ sets, there are $2^{\mathrm{n}}$ possible intersections (here, program combinations; Lex et al. 2014). With seven programs, there were 128 possible program combinations, calculated by $2^{8}$ (including no benefit receipt). We used the ComplexUpset package in $\mathrm{R}$, a package creating complex overlap visualizations for the UpSet plots (Krassowski 2020), to generate family benefit package plots. One major strength of a family benefit package plot is its capacity to display the complex intersection of multiple benefit programs as well as the distribution of different family benefit packages and their corresponding distributions of socioeconomic characteristics. We plot observed family benefit packages and their corresponding distribution of employment status and economic security status to explore the relationships between different components of the family benefit packages used by low-income single-mother families.

To address the second aim of analyzing five-year employment trajectories among lowincome single mothers and the associated sociodemographic characteristics and patterns of family benefit packages, we first used GBTM to identify distinct patterns in monthly employment status across 60 consecutive months among the sample mothers. We performed GBTM using the Traj program for Stata 16 and then assessed the model fit by both objective and subjective criteria, following Nagin (2005). We determined the final five-group solution based on several criteria: the values of the Bayesian information criterion (BIC), the significance of the polynomial change terms, the estimated population size of each trajectory group $(>10 \%)$, the average posterior probability for each group $(>70 \%)$, and a comparison with findings from prior research on employment trajectories. See Supplementary Material A for details on our decision-making process. We used the group membership estimated via the GBTM and multinomial regression analysis to test the associated sociodemographic characteristics for trajectory group membership. We then used descriptive statistics and family benefit package plots to summarize program participation experience by trajectory group.

Finally, to address the third aim of analyzing how low-income single mothers who experienced unstable employment trajectories pieced together different cash and in-kind programs when they transited into and out of employment, we ran a set of logistic regression models to test whether the seven types of program participation and their different combinations of cash and in-kind benefit packages differed by monthly employment status, controlling for IPL and other sociodemographic characteristics. We hypothesize that (1) an out-of-work status is associated with a higher probability of receiving a cash benefit and a benefit package including a cash component because cash benefits theoretically function as primary support; (2) an in-work status is associated with a higher probability of receiving 
CC and a benefit package including CC because employed single mothers need childcare to attend to their work responsibilities, and a CC benefit is strongly tied to employment status.

\section{Results}

\subsection{Patterns of Program Participation and Monthly Family Benefit Packages}

This section presents descriptive statistics on program participation and aggregate monthly family benefit package plots based on 52,200 monthly observations over the five-year study period. Overall, the ever participation rates and the average cumulative benefit duration of the three means-tested basic-needs programs (SNAP, MA, and HA) were higher than those of the three cash programs (UI, SSI, and TANF) and CC. Notably, although TANF and CC primarily served low-income single-mother families with children, less than one-fifth of the sample had ever participated in TANF or CC. On average, sample mothers received only 1.42 benefits monthly (Table 1 ).

Table 1. Patterns of Program Participation for the Seven Benefit Programs.

\begin{tabular}{|c|c|c|c|c|c|c|c|}
\hline & & $\begin{array}{l}\text { All }(\mathrm{N}=870, \\
\text { Obs. }=52,200)\end{array}$ & $\begin{array}{c}\text { Stable } \\
\text { Employment } \\
(\mathrm{N}=384 \\
\text { Obs. }=23,040)\end{array}$ & $\begin{array}{c}\text { Stable Nonem- } \\
\text { ployment } \\
(\mathrm{N}=174 \\
\text { Obs. }=10,440)\end{array}$ & $\begin{array}{c}\text { Slow } \\
\text { Employment } \\
\text { Recovery } \\
(\mathrm{N}=116, \\
\text { Obs. }=6960)\end{array}$ & $\begin{array}{c}\text { Decreasing } \\
\text { Employment } \\
(\mathrm{N}=101 \\
\text { Obs. }=6060)\end{array}$ & $\begin{array}{c}\text { Fast } \\
\text { Employment } \\
\text { Recovery } \\
(\mathrm{N}=95, \\
\text { Obs. }=5700)\end{array}$ \\
\hline \multirow{7}{*}{$\begin{array}{c}\text { Ever } \\
\text { participation } \\
\text { rate }\end{array}$} & UI & $22 \%$ & $12 \%$ & $3 \%$ & $38 \%$ & $51 \%$ & $39 \%$ \\
\hline & SSI & $23 \%$ & $10 \%$ & $58 \%$ & $34 \%$ & $17 \%$ & $13 \%$ \\
\hline & TANF & $19 \%$ & $7 \%$ & $40 \%$ & $32 \%$ & $11 \%$ & $27 \%$ \\
\hline & SNAP & $70 \%$ & $51 \%$ & $86 \%$ & $91 \%$ & $77 \%$ & $81 \%$ \\
\hline & MA & $68 \%$ & $48 \%$ & $88 \%$ & $91 \%$ & $73 \%$ & $83 \%$ \\
\hline & HA & $34 \%$ & $19 \%$ & $49 \%$ & $52 \%$ & $38 \%$ & $43 \%$ \\
\hline & $\mathrm{CC}$ & $18 \%$ & $15 \%$ & $9 \%$ & $24 \%$ & $19 \%$ & $35 \%$ \\
\hline \multirow{7}{*}{$\begin{array}{l}\text { Average } \\
\text { cumulative } \\
\text { benefit } \\
\text { duration } \\
\text { (month) }\end{array}$} & UI & 16.05 & 9.26 & 6.91 & 26.99 & 14.51 & 14.59 \\
\hline & SSI & 31.8 & 18.3 & 43.58 & 24.88 & 17.26 & 32.08 \\
\hline & TANF & 25.4 & 20.84 & 34.69 & 21.46 & 17.46 & 18.26 \\
\hline & SNAP & 41.87 & 33.58 & 50.72 & 47.6 & 32.17 & 50.48 \\
\hline & MA & 32.53 & 25.36 & 46.3 & 32.51 & 24.59 & 34.2 \\
\hline & HA & 40.02 & 38.53 & 48.6 & 36.34 & 35.59 & 37.53 \\
\hline & $\mathrm{CC}$ & 25.58 & 29.68 & 18.19 & 23.67 & 23.99 & 24.51 \\
\hline \multirow{8}{*}{$\begin{array}{l}\text { Program count } \\
\text { Distribution of } \\
\text { program count }\end{array}$} & Avg. & 1.42 & 0.76 & 2.48 & 2.05 & 1.22 & 1.81 \\
\hline & 0 & $39 \%$ & $59 \%$ & $16 \%$ & $18 \%$ & $41 \%$ & $22 \%$ \\
\hline & 1 & $19 \%$ & $19 \%$ & $13 \%$ & $19 \%$ & $22 \%$ & $21 \%$ \\
\hline & 2 & $17 \%$ & $13 \%$ & $16 \%$ & $25 \%$ & $18 \%$ & $26 \%$ \\
\hline & 3 & $15 \%$ & $7 \%$ & $27 \%$ & $22 \%$ & $14 \%$ & $20 \%$ \\
\hline & 4 & $8 \%$ & $2 \%$ & $20 \%$ & $12 \%$ & $4 \%$ & $10 \%$ \\
\hline & 5 & $3 \%$ & $1 \%$ & $8 \%$ & $4 \%$ & $1 \%$ & $2 \%$ \\
\hline & 6 & $0 \%$ & $0 \%$ & $1 \%$ & $0 \%$ & $0 \%$ & $0 \%$ \\
\hline \multirow{3}{*}{$\begin{array}{l}\text { The most } \\
\text { frequent } \\
\text { packages }\end{array}$} & $1 \mathrm{st}$ & SNAP & SNAP & SSI-SNAP-MA & SNAP & SNAP & SNAP \\
\hline & $2 n d$ & SNAP-MA & SNAP-MA & $\begin{array}{l}\text { SSI-SNAP-MA- } \\
\text { HA }\end{array}$ & SNAP-MA & SNAP-MA & SNAP-MA \\
\hline & 3rd & $\begin{array}{c}\text { SNAP-MA- } \\
\text { HA }\end{array}$ & MA & SNAP & $\begin{array}{l}\text { SNAP-MA- } \\
\text { HA }\end{array}$ & SNAP-HA & $\begin{array}{c}\text { SNAP-MA- } \\
\text { HA }\end{array}$ \\
\hline
\end{tabular}

Notes. 1. The average cumulative benefit duration was calculated among mothers who had ever received a given benefit during the five-year study period. 2 . The most frequent benefit packages were analyzed for monthly observations in which single-mother families received at least one benefit out of the seven programs. See the Supplementary Material B for all observed packages.

Figure 1 presents the patterns of monthly family benefit packages with their corresponding distributions across the three economic statuses (i.e., nonemployed; employed, not self-sufficient; employed, self-sufficient) at the top. The sidebar graph on the left shows 
the frequency of participation in each program among the 52,200 monthly observations. The main bar graph and the matrix of program intersections (depicted as lines connecting circles) show the frequencies and their distributions of the 87 most frequent program intersections, which represent $95 \%$ of the total observations. Three bundling patterns deserve attention. First, approximately $40 \%$ of the monthly observations involved no benefit receipt from the seven programs, and among these off-benefit observations, only $25 \%$ reflected an economically secure status (employed and self-sufficient). The majority $(75 \%)$ were associated with a working-poor status (employed but not self-sufficient), and approximately 20\% were associated with a "disconnected" status (nonemployed and no benefits). Second, the five most common family benefit packages were different combinations of the three means-tested in-kind basic needs programs (SNAP, MA, and HA), totaling $30 \%$ of the monthly observations. (We refer to these different bundling patterns collectively as "basic-needs packages" hereafter). Finally, sample mothers used cash benefits and their combinations less frequently and often bundled them with the basic-needs packages.
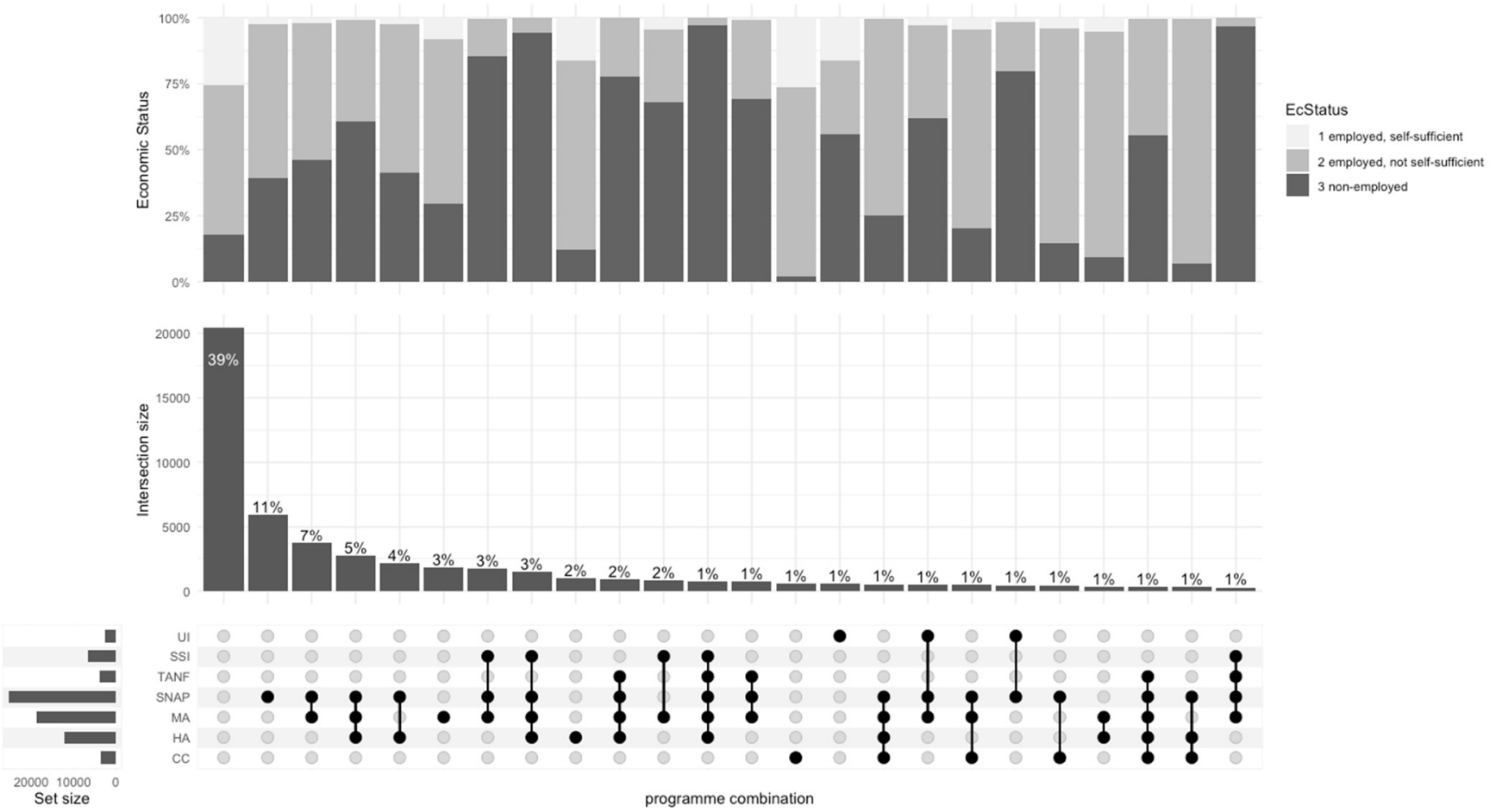

Figure 1. Patterns of Monthly Family Benefit Packages. Notes. 1. The descriptive statistics are based on 52,220 monthly observations. 2. Due to space limitation, 63 combinations of less than $1 \%$ of the observations (totaling $5 \%$ ) are not shown in the figure (available upon request). 3 . The circles in the matrix indicate programs that are part of the family benefit packages.

The variation in the aggregate distribution of employment status by family benefit package suggests that the family benefit packages differ by employment status over time. That is, low-income single mothers with different employment trajectories might have pieced different benefits together during the GR and its four-year aftermath. In the next section, we explore the diverse employment trajectories among the sample mothers and the associated sociodemographic characteristics and program participation patterns.

\subsection{Employment Trajectories, Associated Sociodemographic Characteristics, and Program Participation Patterns}

While the overall monthly employment rate showed a decreasing trend (from the lowest level of $67.2 \%$ in mid-year 1 to the lowest level of $60.6 \%$ in mid-year 5), individual employment trajectories varied significantly among sample mothers. The GBTM results indicated five distinct employment trajectory groups among low-income single mothers: 
stable employment, stable nonemployment, decreasing employment, slow employment recovery, and fast employment recovery. Figure 2 presents the five resulting trajectory groups in terms of the predicted probability of employment over time. We separately summarize each employment trajectory, its associated characteristics, and the descriptive program participation patterns, ordered by each group's estimated proportion in the study population (from large to small).

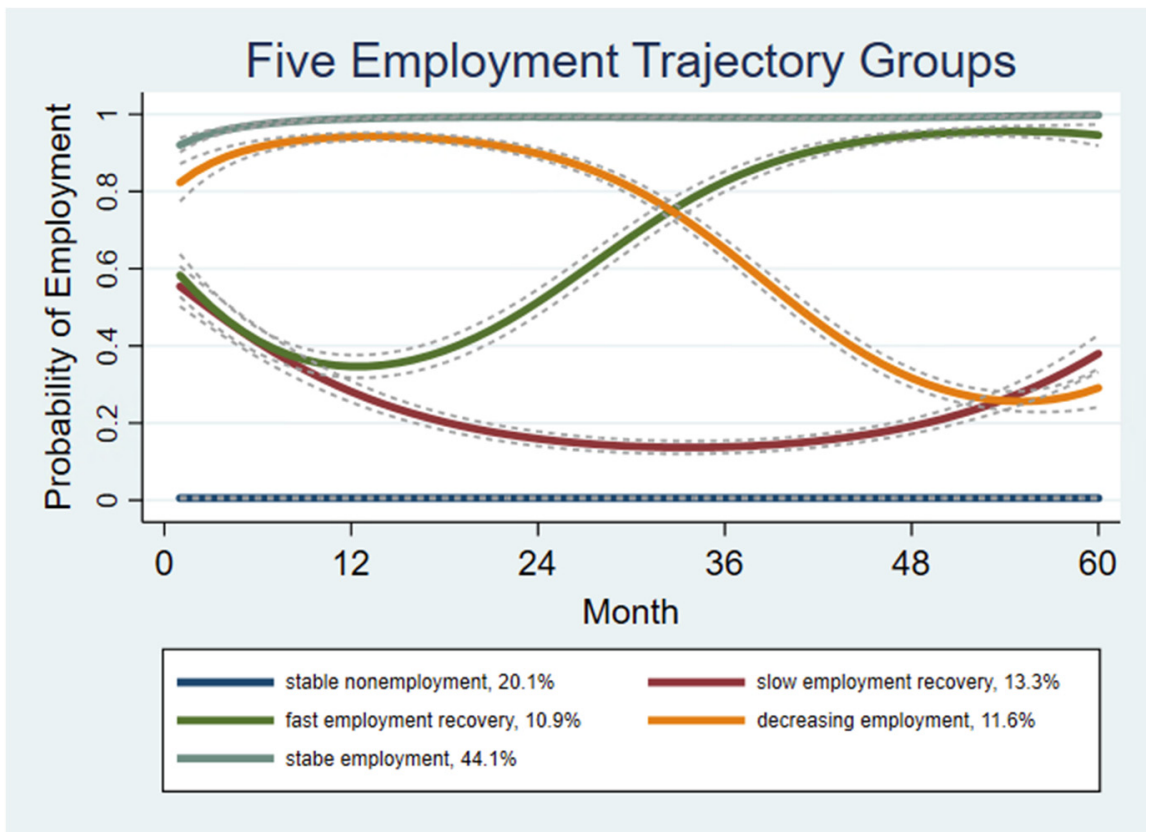

Figure 2. Five Employment Trajectory Groups. Notes. 1. The solid lines represent the predicted probability of employment status over time for the five employment trajectory groups; the dashed lines represent the $95 \%$ confidence intervals of the predicted probabilities. 2 . The $x$-axis represents time in months during the five-year study period from mid-2008 to mid-2013, and the $y$-axis represents the predicted probability of employment.

First, the nearly flat trajectory running across the top represents the stable employment group (approximately $44 \%$ of the study population), with a probability of employment of nearly 1 over time. The multinomial regression model results indicated that holding a high school diploma, not having a work-limiting disability, owning a home, and having a higher IPL in the baseline month significantly predicted a mother's membership in the stable employment trajectory group (Table 2 ). With multiple relatively advantaged sociodemographic characteristics, mothers following a stable employment trajectory had the lowest ever participation rates for five of the seven programs, but $51 \%$ of them still participated in SNAP and $45 \%$ participated in MA. On average, mothers in this group participated in 0.8 programs monthly. While their high IPL and stable employment suggested a need for childcare subsidies, only $15 \%$ of mothers in this group had ever received CC during the five-year study period (Table 1).

Second, the flat trajectory across the bottom of Figure 1 represents the stable nonemployment group (approximately $20 \%$ of the study population), with a probability of employment near zero throughout the five-year period. The multinomial regression model results showed that a work-limiting disability, an older age, and a lower IPL in the baseline month were significantly associated with stable nonemployment group membership (Table 2). Mothers in this group had the highest ever program participation rates for two meanstested cash benefit programs (SSI and TANF) among the five trajectory groups (Table 1). On average, they participated in 2.5 programs monthly. The cash-plus-basic-needs benefit packages were common but not sustainable over time: in approximately $17 \%$ of monthly 
observations (i.e., 10.2 months in five years) there was no support, suggesting a problem of "disconnectedness" among this most economically marginalized group (Table 1).

Table 2. Average Marginal Effects of Baseline Sociodemographic Characteristics on the Probabilities of Group Membership $(\mathrm{N}=870)$.

\begin{tabular}{|c|c|c|c|c|c|}
\hline & (1) & (2) & (3) & (4) & (5) \\
\hline & $\begin{array}{c}\text { Stable } \\
\text { Employment }\end{array}$ & $\begin{array}{c}\text { Stable } \\
\text { Nonemployment }\end{array}$ & $\begin{array}{c}\text { Slow } \\
\text { Employment } \\
\text { Recovery }\end{array}$ & $\begin{array}{l}\text { Decreasing } \\
\text { Employment }\end{array}$ & $\begin{array}{c}\text { Fast Employment } \\
\text { Recovery }\end{array}$ \\
\hline $\begin{array}{c}\text { Income-to-poverty } \\
\text { level }\end{array}$ & $0.002^{* * *}$ & $-0.002^{* * *}$ & 0.000 & $0.001^{* * *}$ & -0.000 \\
\hline Race-Black & 0.015 & -0.032 & 0.009 & 0.031 & -0.023 \\
\hline Race-Hispanic & 0.089 & -0.003 & -0.044 & 0.013 & -0.054 \\
\hline Race-Others & -0.004 & -0.007 & 0.047 & -0.063 & 0.026 \\
\hline $\begin{array}{l}\text { High school } \\
\text { diploma }\end{array}$ & $0.135 * *$ & -0.032 & $-0.113^{* *}$ & -0.027 & 0.037 \\
\hline $\begin{array}{l}\text { Work-limiting } \\
\text { disability }\end{array}$ & $-0.315^{* * *}$ & $0.299 * * *$ & 0.020 & -0.017 & 0.013 \\
\hline Age & -0.001 & $0.005^{* * *}$ & -0.001 & -0.000 & -0.003 \\
\hline \# of children & 0.011 & -0.001 & 0.009 & -0.025 & 0.006 \\
\hline $\begin{array}{c}\text { Age of the } \\
\text { youngest child }\end{array}$ & $0.013^{* *}$ & -0.005 & -0.001 & -0.004 & -0.003 \\
\hline $\begin{array}{l}\text { Marital status- } \\
\text { Wid/div/sep }\end{array}$ & 0.043 & -0.027 & 0.008 & -0.027 & 0.004 \\
\hline Other adults & -0.048 & 0.030 & -0.035 & 0.038 & 0.014 \\
\hline Citizenship status & -0.079 & 0.018 & 0.070 * & 0.051 & -0.060 \\
\hline Homeownership & $0.178^{* * *}$ & -0.017 & -0.049 & -0.049 & $-0.063^{* *}$ \\
\hline $\begin{array}{c}\text { Metro Area } \\
\text { State }\end{array}$ & -0.012 & 0.013 & -0.035 & 0.027 & 0.005 \\
\hline $\begin{array}{l}\text { unemployment } \\
\text { rate }\end{array}$ & -0.032 & -0.000 & 0.031 & -0.001 & 0.003 \\
\hline
\end{tabular}

Notes. $1 .{ }^{*} p<0.05,{ }^{* *} p<0.01,{ }^{* * *} p<0.001$. 2. The reference racial group is White; the reference marital status is never married.

The third group followed a slow employment recovery trajectory (approximately $13 \%$ of the study population), showing a moderate probability of employment of 0.6 that decreased to 0.15 and then increased thereafter to 0.4 (Figure 2). The employment prospects of the mothers in this group were low and sensitive to economic recession, with a slow employment recovery. The results from the multinomial regression model showed that not having a high school diploma in the baseline month significantly predicted slow employment recovery group membership (Table 2). The ever program participation rates in the three basic needs programs for this group were the highest among the five groups. Notably, the similar ever recipiency rates (approximately 35\%) and average cumulative benefit durations for the three cash benefits (UI, SSI and TANF) suggested that these programs might play equivalent roles in family benefit packages for this group (Table 1).

The fourth group showed decreasing employment (approximately $12 \%$ of the study population), with the estimated probability of employment decreasing from 0.9 to 0.2 (Figure 2). Mothers in this group typically experienced job losses and did not return to employment by the end of 2013. The results from the multinomial regression model showed that only a higher IPL in the baseline month was associated with decreasing employment group membership, suggesting that mothers in this group generally represented the average sociodemographic characteristics of the sample (Table 2). The mothers in this group had the highest UI participation rate (51\%), with an average cumulative benefit duration of 14.5 months. Notably, the cumulative benefit duration for the other six programs was the lowest among the five groups, suggesting that mothers in this group used social benefits temporarily to sustain their families (Table 1). 
In contrast to the third group, a fifth group, constituting approximately $11 \%$ of the population, showed a fast employment recovery trajectory, beginning with a moderate probability of employment of 0.6 that decreased to a level lower than 0.4 in the first year and then increased thereafter to nearly 1 in the final year. The majority in this group experienced job instability during the GR, but regained stable employment during the post-recessionary period. The results from the multinomial regression model showed that not owning a home in the baseline month were associated with fast employment recovery group membership (Table 2). Program participation statistics show that these mothers stood out for having the highest ever participation rate in CC (35\%) among the five groups, with an average cumulative benefit duration of 24.51 months. However, on average, they participated in only 1.8 programs monthly (Table 1 ).

In sum, our analysis showed that program participation and family income packages varied significantly among mothers following different employment trajectories and with different sociodemographic characteristics. However, approximately $82 \%$ of our study sample remained under $200 \%$ IPL at the end of the study period, suggesting that the majority of low-income single-mother families were struggling to achieve self-sufficiency. Given that family benefit packages are sensitive to changing work status in a work-based welfare system, it is necessary to understand how different family benefit packages support mothers experiencing employment instability. Monthly observations from mothers experiencing three unstable employment trajectories (decreasing employment, fast employment recovery, and slow employment recovery) provided rich information for comparing in-work and out-of-work monthly family benefit packages by controlling for other time-varying sociodemographic characteristics. We restrict our analysis to this subpopulation in the next section.

\subsection{In-Work and Out-of-Work Monthly Family Benefit Packages Used by Mothers with Unstable Employment Trajectories}

Table 3 presents the results from a set of logistic regression models that tested the association between monthly employment status and different types of program participation and bundling ${ }^{1}$ for mothers with unstable employment trajectories. Figure 3a shows the predicted probabilities of possible combinations of three types of benefits (i.e., cash, basic needs, and childcare) by employment status, and Figure 3b shows the predicted probabilities for participation in each of the seven programs by employment status, holding IPL, and other sociodemographic characteristics constant.

When mothers transited from an out-of-work status to an in-work status, the probability of receiving a basic-needs-only (BNOnly) package significantly increased from 0.32 to 0.48 , and that of receiving a CC-plus-basic-needs (CCBN) package significantly increased from 0.04 to 0.08 (Figure 3a). These patterns suggest that although CC is crucial for mothers' transit from unemployment to employment, family benefit packages including a CC were rarely used by mothers who experienced unstable employment trajectories.

When mothers transited from an in-work status to an out-of-work status, their probability of receiving a cash-plus-basic-needs (CashBN) package increased significantly, from 0.13 to 0.27 , and their probability of receiving a cash-only package (CashOnly) increased from 0.01 to 0.05 (Figure 3a). UI largely drove these patterns. As Figure 3b shows, when mothers transitioned from an in-work status to an out-of-work status, the probability of UI participation significantly increased by 0.2 , while the probability of TANF and SSI participation did not significantly change, suggesting that UI played a more important role than other cash benefit programs in stabilizing family income. However, we also found that the probability of no program participation was 0.27 among the out-of-work observations. This probability highlighted that low-income single mothers faced a substantial risk of being disconnected in the US welfare system. 
Table 3. Results of the Logistic Regression Models.

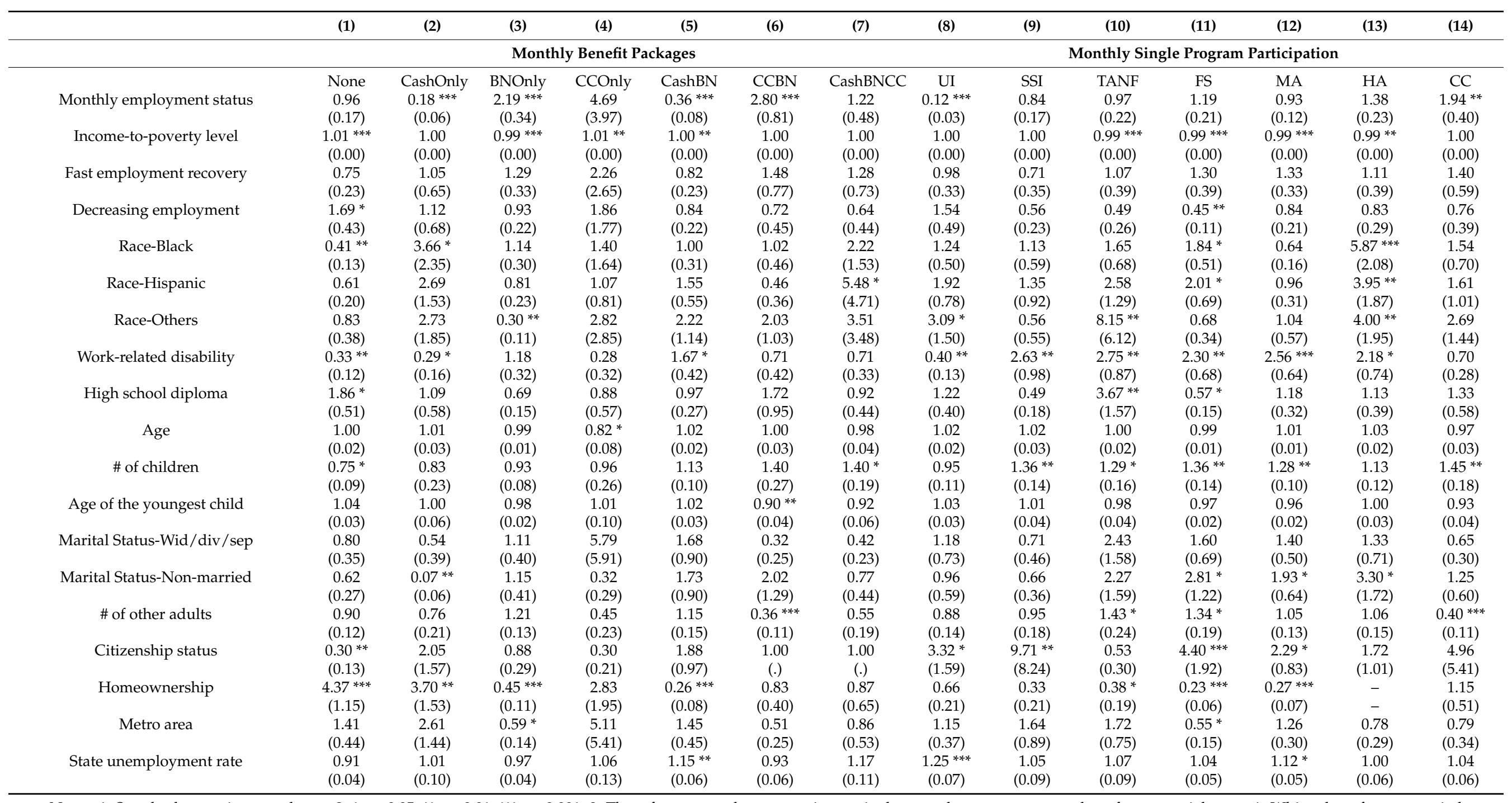

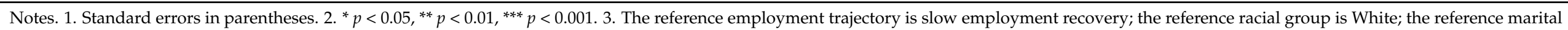
status is married. 4 . Monthly benefit packages consider all possible combinations of cash, basic needs, and childcare benefits. 


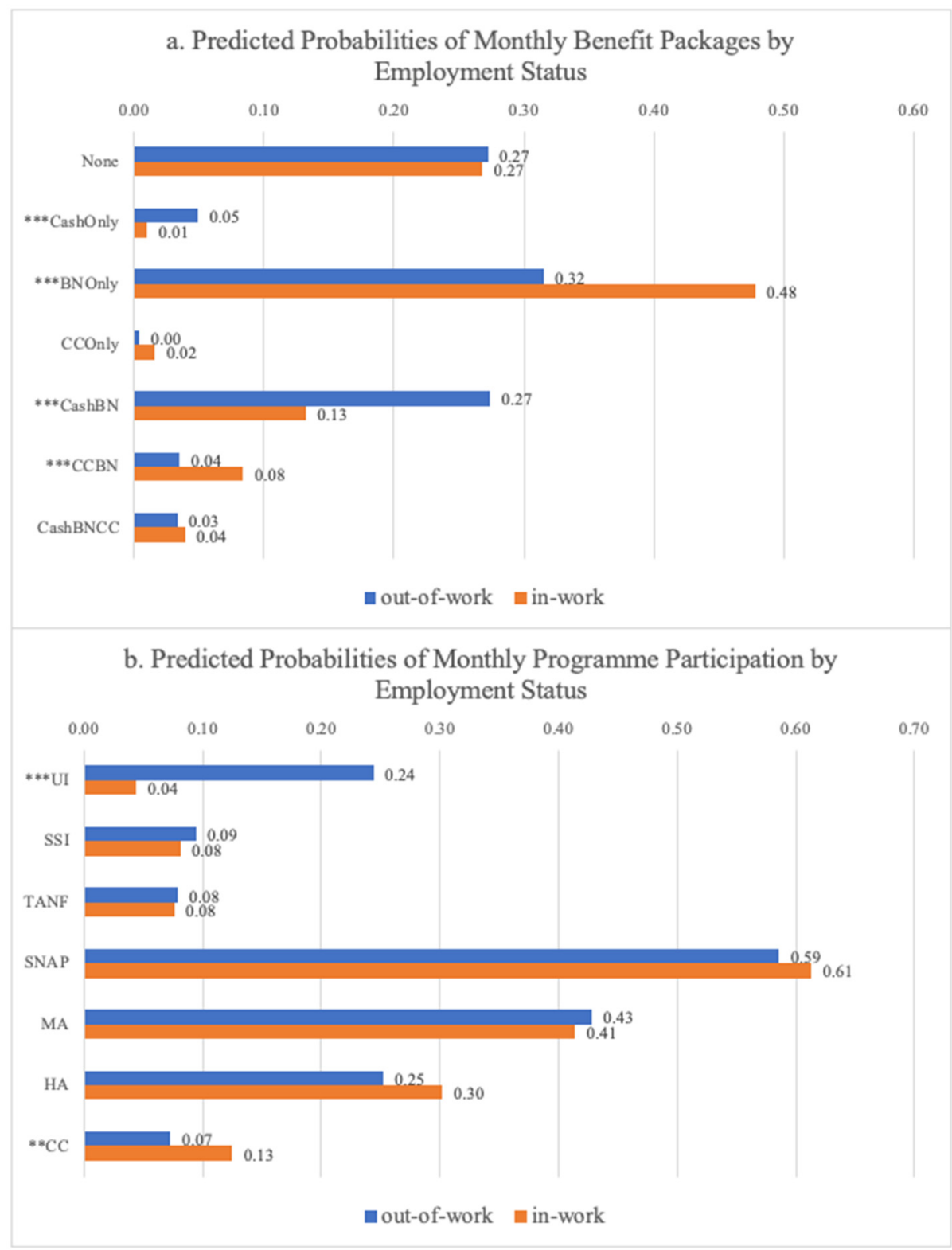

Figure 3. Predicted Probabilities of Monthly Benefit Packages and Program Participation. Notes. 1. ${ }^{* *} p<0.01,{ }^{* * *} p<0.001$. 2. Predicted probabilities are estimated from the models in Table 3.

\section{Discussion}

This research addresses a significant gap in the social welfare literature by analyzing patterns of family benefit packages and employment status over time among low-income single-mother families in the US work-based system. Advancing prior research on family benefit packages and multiple program participation, we are the first to apply UpSet plots, a novel set and intersection visualization tool, to reveal the patterns of monthly family benefit packages. Our analysis shows that the most common packages bundle in-kind basic-needs benefits that address food, health, and housing needs. These programs' lack of conditionality on work and shared administration processes could explain the more sustainable support received from these basic needs programs than from cash or childcare programs (Allard et al. 2015). Our results show that cash programs often supplemented inkind benefit packages in the US system, which is inconsistent with theoretical perspectives on family benefit packages that cash benefits function as primary resources (Seefeldt and Horowski 2012). In particular, the TANF program, which was designed to provide work 
support to low-income mothers with children, played a very limited role in the US workbased welfare system during the GR (Chang 2015; Chang and Romich 2021; Seefeldt 2017).

The successful rhetoric of welfare reform (in terms of reduced welfare caseload and increased work participation among low-income single mothers) was questionable during the GR and its aftermath due to mass unemployment and underemployment. Our GBTM of the five-year employment patterns and the follow-up analysis provide new insights into the heterogeneous employment trajectories and program participation experiences of low-income single mothers. First, we found that only approximately $43 \%$ of the study population maintained stable employment following the GR. Mothers with a stable employment trajectory tended to have relatively advantaged sociodemographic characteristics and used only 1-2 in-kind benefits. The increasing average IPL (from 122\% in month 1 to $213 \%$ in month 60) suggested that constant basic-needs or childcare benefits, in combination with earnings from steady employment, could be a pathway to transition into a secure economic status. Second, mothers following a stable nonemployment trajectory $(18 \%)$ tended to have multiple barriers to employment (e.g., old age, a low education level, disability, and a young child), and they often used benefit packages that combined basic-needs and disability cash benefits (SSI). However, our analysis highlights that approximately $16 \%$ of monthly observations (i.e., an average of 9.6 months in five years) showed no earnings or benefits for this economically marginalized group. Studies have indicated that many US families without cash income take on debt to sustain their economic lives (Seefeldt 2017). Disconnection from both the welfare and labor market systems often correlates with intense poverty and lower child well-being (Cancian et al. 2014; Kwon and Meyer 2011; Slack et al. 2014). Finally, the GBTM findings revealed that a substantial proportion (approximately $40 \%$ ) of low-income single mothers experienced unstable employment following the GR. Our subgroup analysis showed that a low education level was associated with a low and unstable probability of employment for mothers following the slow employment recovery trajectory. This finding suggests that providing education opportunities alongside social benefit packages may help those without a high school diploma advance their employment prospects and earnings.

This research also clarifies the previously obscure relationship between different family benefit packages and changes in employment status in the US work-based welfare system. Our logistic regression analysis suggested that strengthening UI benefits and childcare subsidies in addition to basic-needs benefits is crucial to stabilize economic resources for low-income single mothers who experience unstable employment trajectories. However, the high probability of no program participation among the out-of-work monthly observations indicated that the low-income single mothers did not consistently rely on the seven key welfare programs but instead faced a high risk of being disconnected from both the welfare system and the labor market. Our findings are particularly relevant to the pandemic recession. We anticipate that the proportion of low-income single mothers who cannot maintain stable employment during this time and in the recovery period will be considerably larger than the $60 \%$ estimated based on the data from the GR. The business and school shutdown particularly disadvantages low-income single mothers, who are facing double burdens from their responsibilities as breadwinners and caregivers in their families.

We discuss a few limitations of our analysis and suggest directions for future research on family benefit packages to advance the economic well-being of low-income working families. First, our family benefit plots identified the most frequent programs and their combinations by employment pattern over a five-year period (a full set of family benefit package plots by trajectory group is available online, see supplementary material B). However, our analysis cannot identify the sequence of the benefits that low-income singlemother families use. For example, when a mother lost her job, did she use UI benefits before, after, or concurrently with the in-kind benefit package? With an understanding of the most relevant benefit packages for different employment trajectory groups, future research can conduct sequence analysis to address this question. The findings can inform practitioners 
regarding how to coordinate the most relevant resources and assist families in navigating the complex social welfare system to build customized family benefit packages. Second, although we used longitudinal data to explore the relationship between family benefit packages and employment status over time, we cannot claim a causal relationship between program participation and employment outcomes. Some labor economists and conservative policymakers have raised concerns about the strong work disincentive effect created by the high hypothetical marginal tax rate of multiple-benefit receipt (Kosar and Moffitt 2017; Mulligan 2012). Our findings indicated that the average program count considering the seven focal programs was only 1.42, suggesting that mothers did not take advantage of all benefit programs, as studies on the marginal tax rate assume. Instead, our findings confirmed that packaging UI- or CC-plus-basic needs benefits is important for families to maintain economic well-being when transitioning into and out of employment. Future research can contribute to policy debates by examining the causal relationship between different benefit packages and long-term employment outcomes via causal modeling.

\section{Conclusions}

A historical underinvestment in public social programs hinders the progress toward ensuring the economic well-being of vulnerable working families with children in the United States. Cross-country comparison research involving 17-high-income countries has shown that single parent families in the US are worst off that they have the highest rate of low-wage employment, the highest post-transfer poverty rate, and a later age for public early childhood education; it is also the only one of the studied countries that lacks entitled paid parental leave and a child allowance program (Casey and Maldonado 2012). Whereas the average country in the Organization for Economic Co-operation and Development invested $2.6 \%$ of its gross domestic product (GDP) in all types of child benefits (of which almost half consisted of cash transfers), the United States spent less than 1.2\% of its GDP on all child benefits in 2009 (Cho 2017). Yet, that year was a historic high, reflecting the American Recovery and Reinvestment Act of 2009 (ARRA 2009), which expanded several social benefit programs in response to the increasing economic hardship of the GR (Chang 2015; Chang and Romich 2021).

This research presents a nuanced picture of monthly family benefit package patterns and employment trajectories among low-income single mothers during and after the GR. Our findings provide insights into benefit packages that help low-income working families stabilize their economic well-being and facilitate a discussion on the elements of the recently released American Families Plan (AFP) of 2021 proposed by President Joseph Biden's administration. If it passes, the AFP will provide comprehensive social benefits to working families by investing in income support programs, education, childcare, health care, and paid family and medical leave (White House 2021). Several policy reform directions align well with our key findings and arguments.

Based on our longitudinal empirical findings, we argue that a robust family benefit package that can help working families supplement income loss due to job separation or unstable, low-wage jobs should include cash income as a primary benefit. The prepandemic US work-based welfare system failed to provide effective and adequate support when people need cash during economic downturns. To strengthen the US work-based welfare system, UI should function as the first line of cash benefits for unemployed workers. However, pre-pandemic eligibility rules disqualified those without a steady employment history or who earned very low wages in recent quarters. Low-income single mothers often underutilize UI due to perceived ineligibility or nonmonetary requirements (e.g., leaving jobs for family reasons; Chang 2020). Reforming the eligibility rules to improve accessibility for low-wage workers would benefit low-income single-mother families (Rangarajan and Razafindrakoto 2004). The pandemic legislation Coronavirus Aid, Relief, and Economic Security Act of 2020 (CARES Act 2020) created two temporary programs to broaden unemployment benefit coverage- the Pandemic Emergency Unemployment Compensation and the Pandemic Unemployment Assistance-which were extended by 
the March 2021 American Rescue Plan Act (ARPA 2021) through September 2021. The follow-up AFP will enhance theses earlier efforts on UI system modernization, equitable access, and adequate benefit by making permanent UI reforms, if it passes into law (White House 2021).

Childcare support and education are another two key components for strengthening the US work-based welfare system. The allocations of more federal funding to accessible and adequate childcare subsidies, early childhood education, and postsecondary education are essential for the study population. The AFP would improve the employment prospects and the economic well-being of low-income single mother families by expanding subsidies for affordable, high quality childcare and preschool, providing tuition-free two-year community college, and making colleges affordable for students from low-income families (White House 2021).

Our findings challenge several pre-pandemic welfare reform proposals under Donald Trump's Administration that would have tightened access to means-tested basic-needs programs (i.e., SNAP, MA, and HA) through more stringent work requirements and time limits. These proposed reforms would further weaken the US welfare system (Pavetti 2018). We anticipate that the burdens of meeting stricter work requirements and recertifying eligibility would make the in-kind benefits less relevant to low-income families, as our evidence on low TANF participation suggests.

In light of the current economic crisis triggered by the pandemic, our US-based research contributes to the policy debate on a new social welfare scheme that emphasizes an unconditional, guaranteed monthly income benefit (Patel and Kariel 2021). However, the concerns about an untargeted benefit for those most in need, high benefit cost, and potential impact on reduced labor supply make this new welfare scheme less favorable for scaling up to a federal program than other in-work tax benefits (such as the EITC and the CTC) in the US political environment (Hoynes and Rothstein 2019). The 2021 ARPA expanded these tax benefits, and the AFP would extend those expansion. The reformed CTC payment method, changing from annual payments to monthly payments, would increase monthly income resources available for working families with children.

The AFP's proposal for a permanent, entitled paid family and medical leave program to help working families to reconcile their work and caregiving responsibilities would respond to a clear need. Without such a component in family benefit packages, the new demands of home care/schooling imposed by the pandemic or similar crises in the future will make it harder if not impossible for low-income single mothers to maintain their economic well-being and recover from the recession.

Supplementary Materials: The following are available online at https:/ /www.mdpi.com/article/10 $.3390 / \mathrm{jrfm} 14060265 / \mathrm{s} 1$.

Author Contributions: Conceptualization, Y.-L.C. and C.-F.W.; methodology, analysis, and visualization, Y.-L.C.; writing-original draft preparation, review and editing, Y.-L.C. and C.-F.W. All authors have read and agreed to the published version of the manuscript.

Funding: The research was funded by a research grant awarded to Yu-Ling Chang by the Institute for Research on Labor and Employment (IRLE) at the University of California, Berkeley. Additionally, Chi-Fang Wu received support from the University of Illinois at Urbana-Champaign Campus Research Grant. Findings and conclusions are those of the authors and do not necessarily reflect the views of the supporting agency.

Institutional Review Board Statement: Not applicable.

Informed Consent Statement: Not applicable.

Acknowledgments: The authors thank Mary Keegan Eamon, Kathryn Epstein, and the anonymous reviewers for their comments on the earlier drafts. The authors thank Woojin Jung, who was a graduate student research assistant for the research project "Multiple Income Support Program Participation and Long-Term Employment and Earnings Trajectories among Single-Mother Families" funded 
by the IRLE. Publication made possible in part by support from the Berkeley Research Impact Initiative (BRII) sponsored by the UC Berkeley Library.

Conflicts of Interest: The authors declare no conflict of interest.

\section{Notes}

1 For example, we used the terms cash-plus-basic-needs package (a bundling pattern of any combination of UI, SSI, or TANF plus any combination of SNAP, MA, or HA) and CC-plus-basic-needs package (a bundling pattern of CC and any combination of SNAP, MA, or HA). We did not include the negligible cash-plus-CC package (almost no observations) due to model nonconvergence.

\section{References}

Achdut, Netta, and Haya Stier. 2016. Long-Term employment and earnings patterns of welfare recipients: The Role of the local labor market. Social Service Review 90: 647-82. [CrossRef]

Acs, Gregory, and Pamela Loprest. 2004. Leaving Welfare: Employment and Well-Being of Families That Left Welfare in the Post-Entitlement Era. Kalamazoo: WE Upjohn Institute. [CrossRef]

Allard, Scott W., Maria V. Wathen, and Sandra K. Danziger. 2015. Bundling public and charitable supports to cope with the effects of the Great Recession. Social Science Quarterly 96: 1348-62. [CrossRef]

American Rescue Plan Act of 2021. 2021, P.L. 117-2 (11 March 2011). Available online: https:/ /www.congress.gov/bill/117th-congress / house-bill/1319 (accessed on 27 May 2021).

American Recovery and Reinvestment Act of 2009. 2009, P.L. 111-5, 123 Stat. 115 (17 Februaruy 2009). Available online: https: / / www.congress.gov/111/plaws/publ5/PLAW-111publ5.pdf (accessed on 27 May 2021).

Bitler, Marianne, and Hilary W. Hoynes. 2010. The State of the Social Safety Net in the Post-Welfare Reform Era. Brookings Papers on Economic Activity 71-147. [CrossRef]

Bitler, Marianne, and Hilary W. Hoynes. 2016. The more things change, the more they stay the same? The safety net and poverty in the Great Recession. Journal of Labor Economics 34: S403-S444. [CrossRef]

Bitler, Marianne, Hilary Hoynes, and Elira Kuka. 2017. Child poverty, the Great Recession, and the social safety net in the United States. Journal of Policy Analysis and Management 36: 358-89. [CrossRef]

Blank, Rebecca M. 2006. What did the 1990s welfare reform accomplish? In Public Policy and Income Distribution. Edited by Alan J. Auerbach, David Card and John M. Quigley. New York: Russell Sage Foundation, pp. 33-79.

Cancian, Maria, Robert H. Haveman, Daniel R. Meyer, and Barbara Wolfe. 2002. Before and after TANF: The economic well-being of women leaving welfare. Social Service Review 76: 603-41. [CrossRef]

Cancian, Maria, Daniel R. Meyer, and Chi-Fang Wu. 2005. After the revolution: Welfare patterns since TANF implementation. Social Work Research 29: 199-214. [CrossRef]

Cancian, Maria, Eunhee Han, and Jennifer L. Noyes. 2014. From multiple program participation to disconnection: Changing trajectories of TANF and SNAP beneficiaries in Wisconsin. Children and Youth Services Review 42: 91-102. [CrossRef]

Coronavirus Aid, Relief, and Economic Security Act of 2020. 2020, P.L. 116-136 (27 March 2020). Available online: https://www. congress.gov/116/plaws/publ136/PLAW-116publ136.pdf (accessed on 27 May 2021).

Casey, Timothy, and Laurie Maldonado. 2012. Worst Off-Single-Parent Families in The United States. In A Cross-National Comparison of Single Parenthood in the US and Sixteen Other High-Income Countries. New York: Legal Momentum, the Women's Legal Defense and Education Fund.

Chang, Yu-Ling. 2015. Re-Examining the U.S. Social Safety Net for Working-Age Families: Lessons From the Great Recession and Its Aftermath. Journal of Policy Practice 14: 139-61. [CrossRef]

Chang, Yu-Ling. 2020. Unequal Social Protection under the Federalist System: Three Unemployment Insurance Approaches in the United States, 2007-2015. Journal of Social Policy 49: 189-211. [CrossRef]

Chang, Yu-Ling, and Jennifer L. Romich. 2021. The US Safety Net since the Great Recession: Trends and Reforms, 2007-2017. Social Work 66: 29-37. [CrossRef]

Cho, Esther Yin-Nei. 2017. Child Benefit Portfolios Across OECD Countries. Social Indicators Research 132: 1099-15. [CrossRef]

Danziger, Sheldon, Colleen M. Heflin, Mary E. Corcoran, Elizabeth Oltmans, and Hui-Chen Wang. 2002. Does it pay to move from welfare to work? Journal of Policy Analysis and Management 21: 671-92. [CrossRef]

Danziger, Sandra K., Sheldon Danziger, Kristin S. Seefeldt, and H. Luke Shaefer. 2016. From welfare to a work-based safety net: An incomplete transition. Journal of Policy Analysis and Management 35: 231-38. [CrossRef]

Eamon, Mary Keegan, and Chi-Fang Wu. 2013. Employment, economic hardship, and sources of assistance in low-income, singlemother families before versus during and after the Great Recession. Journal of Poverty 17: 135-56. [CrossRef]

Finifter, David H., and Mark A. Prell. 2013. Participation in the Supplemental Nutrition Assistance Program (SNAP) and Unemployment Insurance: How Tight Are the Strands of the Recessionary Safety Net? Washington: US Department of Agriculture, Economic Research Service.

Fortin, Nicole M., and Thomas Lemieux. 1997. Institutional changes and rising wage inequality: Is there a linkage? Journal of Economic Perspectives 11: 75-96. [CrossRef]

Gilman, Michele Estrin. 2006. Fighting poverty with faith: Reflections on ten years of Charitable Choice. Journal of Gender, Race 10: 395. 
Hancock, Ange-Marie. 2003. Contemporary Welfare Reform and the Public Identity of the “Welfare Queen”. Race, Gender E Class 10: 31-59.

Hardy, Bradley, Timothy Smeeding, and James P. Ziliak. 2018. The changing safety net for low-income parents and their children: Structural or cyclical changes in income support policy? Demography 55: 189-221. [CrossRef]

Hetling, Andrea, Jinwoo Kwon, and Correne Saunders. 2015. The Relationship between State Welfare Rules and Economic Disconnection among Low-Income Single Mothers. Social Service Review 89: 653-85. [CrossRef]

Hoynes, Hilary, and Jesse Rothstein. 2019. Universal Basic Income in the United States and Advanced Countries. Annual Review of Economics 11: 929-58. [CrossRef]

Johnson, Rucker C. 2007. Wage and job dynamics after we welfare reform: The importance of job skills. Research in Labor Economics 26: 231-98. [CrossRef]

Kim, Jeounghee, and Myungkook Joo. 2009. Work-related activities of single mothers before and after welfare reform. Monthly Labor Review 132: 3-17.

Kosar, Gizem, and Robert A. Moffitt. 2017. Trends in cumulative marginal tax rates facing low-income families, 1997-2007. Tax Policy and the Economy 31: 43-70. [CrossRef]

Krassowski, Michał. 2020. ComplexUpset. Available online: https:/ / github.com/krassowski/complex-upset (accessed on 29 May 2020).

Kwon, Hyeok Chang, and Daniel R. Meyer. 2011. How do economic downturns affect welfare leavers? A comparison of two cohorts. Children and Youth Services Review 33: 588-97. [CrossRef]

Lee, Chulhee. 2008. Rising family income inequality in the United States, 1968-2000: Impacts of changing labor supply, wages, and family structure. International Economic Journal 22: 253-72. [CrossRef]

Lex, Alexander, Nils Gehlenborg, Hendrik Strobelt, Romain Vuillemot, and Hanspeter Pfister. 2014. UpSet: Visualization of intersecting sets. IEEE Transactions on Visualization and Computer Graphics 20: 1983-92. [CrossRef]

Mattingly, Marybeth J., Kristin Smith, and Jessica A. Bean. 2011. Unemployment in the Great Recession: Single Parents and Men Hit Hard. Issue Brief No.35. Durham: Carsey Institute.

Meyers, Marcia. 2007. The institutional architecture of antipoverty policy in the United States: Looking back, looking ahead. Focus 25: $58-62$.

Meyers, Marcia K, and Janet C. Gornick. 2009. Beyond the Safety Net: Supporting the Economic Security of Working Poor Families. In Making the Work-Based Safety Net Work Better: Forward-Looking Policies to Help Low-Income Families. Edited by Carolyn J. Heinrich and Joh Karl Scholz. New York: Russell Sage Foundation, pp. 261-90.

Meyers, Marcia K., Janet C. Gornick, and Laura R. Peck. 2001. Packaging support for low-income families: Policy variation across the United States. Journal of Policy Analysis and Management 20: 457-83. [CrossRef]

Moffitt, Robert A. 2013. The Great Recession and the social safety net. The ANNALS of the American Academy of Political and Social Science 650: 143-66. [CrossRef]

Moffitt, Robert A. 2014. Multiple Program Participation and the SNAP Program. Research, Discussion Paper Series, DP, 2014-04; Lexington: University of Kentucky Centre for Poverty.

Mulligan, Casey B. 2012. The Redistribution Recession: How Labor Market Distortions Contracted the Economy. New York: Oxford University Press. [CrossRef]

Nagin, Daniel S. 2005. Group-Based Modeling of Development. Cambridge: Harvard University Press. [CrossRef]

O'leary, Christopher J., and Ken Kline. 2014. Use of Supplemental Nutritional Assistance Program Benefits by Unemployment Insurance Applicants in Michigan during the Great Recession. Kalamazoo: WE Upjohn Institute.

Patel, Salil B., and Joel Kariel. 2021. Universal basic income and covid-19 pandemic. BMJ 372: n193. [CrossRef] [PubMed]

Pavetti, LaDonna. 2018. TANF Studies Show Work Requirement Proposals for Other Programs Would Harm Millions, Do Little to Increase Work. Centre on Budget and Policy Priorities website. Available online: https://www.cbpp.org/research/family-income-support/tanfstudies-show-work-requirement-proposals-for-other-programs-would (accessed on 29 June 2019).

Queen, Edward. 2017. History, Hysteria, and Hype: Government Contracting with Faith-Based Social Service Agencies. Religions 8: 22. [CrossRef]

Rangarajan, Anu, and Carol Razafindrakoto. 2004. Unemployment Insurance as a Potential Safety Net for TANF Leavers: Evidence from Five States. Princeton: Mathematica Policy Research, Inc.

Seccombe, Karen. 1999. "So You Think I Drive a Cadillac?": Welfare Recipients' Perspectives on the System and Its Reform. Boston: Allyn \& Bacon.

Seefeldt, Kristin S. 2017. Serving No One Well: TANF Nearly Twenty Years Later. Journal of Sociology E Social Welfare 44: 3-28.

Seefeldt, Kristin, and Meredith Horowski. 2012. The continuum of connection: Low-income families and economic support during the Great Recession. In National Poverty Centre Working Paper No. 12-11. Ann Arbor: National Poverty Centre.

Seefeldt, Kristin S., and Heather Sandstrom. 2015. When there is no welfare: The income packaging strategies of mothers without earnings or cash assistance following an economic downturn. The Russell Sage Foundation Journal of the Social Sciences 1: 139-58. [CrossRef]

Seefeldt, Kristin S., John David Graham, and Gordon Abner. 2013. America's Poor and the Great Recession. Bloomington: Indiana University Press. 
Slack, Kristen S., Bomi Kim, Mi-Youn Yang, and Lawrence M. Berger. 2014. The economic safety net for low-income families with children. Children and Youth Services Review 46: 213-19. [CrossRef]

Waring, Melody K., and Daniel R. Meyer. 2020. Welfare, work, and single mothers: The Great Recession and income packaging strategies. Children and Youth Services Review 108: 104585. [CrossRef]

Westat and Mathematica Policy Research. 2001. Survey of Income and Program Participation Users' Guide (Supplement to the Technical Documentation. Washington: U.S. Census Bureau.

White House. 2021. Fact Sheet: The American Families Plan. Available online: https://www.whitehouse.gov/briefing-room/ statements-releases / 2021/04/28/fact-sheet-the-american-families-plan/ (accessed on 27 May 2021).

Wood, Robert G., Quinn Moore, and Anu Rangarajan. 2008. Two steps forward, one step back: The uneven economic progress of TANF recipients. Social Service Review 82: 3-28. [CrossRef]

$\mathrm{Wu}$, Chi-Fang. 2011. Long-term employment and earnings among low-income families with children. Children and Youth Services Review 33: 91-101. [CrossRef]

Wu, Chi-Fang, Maria Cancian, and Daniel R. Meyer. 2008. Standing still or moving up? Evidence from Wisconsin on the long-term employment and earnings of TANF participants. Social Work Research 32: 89-103. [CrossRef]

Yang, Mi-Youn, Bomi Kim Hirsch, Kristen S. Slack, and Lawrence M. Berger. 2019. Strategies for packaging income and means-tested benefit sources among WIC program participants. Journal of the Society of Social Work and Research 10: 459-75. [CrossRef] 